\title{
EFEKTIVITAS PSIKOEDUKASI KELUARGA DALAM MENURUNKAN BEBAN KELUARGA PADA KELUARGA PASIEN ULKUS DIABETES MELITUS
}

\author{
Aisyah Dzil Kamalah ${ }^{1}$, Ahsan $^{2}$, Heri Kristianto ${ }^{2}$ \\ ${ }^{1}$ Program Studi Sarjana Keperawatan, Universitas Muhammadiyah Pekajangan Pekalongan, Jl. Raya \\ Ambokembang No.8, Kambang Tengah, Ambokembang, Kec. Kedungwuni, Pekalongan, Jawa Tengah, \\ Indonesia 51172 \\ ${ }^{2}$ Program Magister Keperawatan Fakultas Kedokteran Universitas Brawijaya, Jl. Veteran, Ketawanggede, Kec. \\ Lowokwaru, Kota Malang, Jawa Timur 65145 \\ *aisyah.kamalah@gmail.com
}

\begin{abstract}
ABSTRAK
Ulkus diabetes mellitus merupakan komplikasi dari penyakit diabetes mellitus yang digolongkan dalam penyakit luka kronik sehingga biaya yang digunakan dalam penyembuhan relatif banyak. Kondisi pasien ulkus yang tidak stabil menyebabkan masalah psikososial pada keluarga, seperti beban pada keluarga. Beban keluarga dapat mempengaruhi keluarga dalam merawat pasien ulkus DM. Penelitian ini bertujuan untuk mengetahui efektifitas psikoedukasi keluarga dalam menurunkan beban keluarga dalam merawat pasien ulkus DM. Desain penelitian ini adalah quasi experimental pre-post test with control group. Cara pengambilan sampel pada penelitian ini adalah dengan purposive smpling. Jumlah sampel sebanyak 30 caregiver yang terbagi dalam kelompok perlakuan dan kelompok kontrol. instrumen yang digunakan adalah The Burden Scale untuk mengukur beban keliarga. Hasil uji validitas dan reliabilitas menunjukkan $\mathrm{r}$ tabel $(0,361) \mathrm{r}$ hitung $(0,765)$ dan $\mathrm{r}$ alpha / koefisien reliabilitas $(0,907)$. Psikoedukasi keluarga dilakukan dalam 5 sesi. Hasil penelitian menunjukkan $\mathrm{p}$ value $(0,000)<\alpha(0,05)$ baik. Psikoedukasi efektif dalam menurunkan beban keluarga.
\end{abstract}

Kata kunci: beban keluarga, pasien ulkus diabetes mellitus, psikoedukasi keluarga

\section{THE EFFECTVENESS OF FAMILY PSYCHOEDUCATION IN REDUCES FAMILY BURDEN IN THE FAMILY WITH ULCERS DIABETIC PATIENTS}

\begin{abstract}
Ulcers Diabetes Mellitus is a complication of Diabetes Mellitus which is classified in wound chronic, it needs a lot of cost to recovery a. Unstable physical and emotional condition of a patient can make psychosocial problems such as burden family. Burden can affect the family in taking care of patients with diabetic ulcers. This study aimed to determine the effectiveness of family psychoeducation in reducing family burden when taking care of patients with diabetic ulcers in Malang. This design of study was quasi - experimental pre - post test with control group. The sampling method used was purposive sampling with 30 caregiver as total sample and divided into treatment group and control group. The instruments of this research were The Burden Scale to measure the family burden. The results of the validity and reliability test show $r$ table $(0.361) r$ count $(0.765)$ and $r$ alpha / reliability coefficient (0.907). Family psychoeducation was conducted in five sessions. The results showed the $p$ value $(0.000)<\alpha(0.05)$ in burden family. Psychoeducation is effective in reducing family burden.
\end{abstract}

Keywords: burden family, patients with ulcer diabetes mellitus, family psychoeducation.

\section{PENDAHULUAN}

Diabetes Mellitus (DM) adalah sekumpulan gejala yang diakibatkan oleh tidak ada atau kurang efektifnya hormon insulin yang dihasilkan oleh pankreas. Insulin adalah kunci tubuh untuk mendapatkan glukosa yang dapat digunakan dalam bentuk energi (International Diabetes Federation, 2013).
Berdasarkan perolehan data Badan Pusat Statistik (BPS) menyatakan bahwa akan terjadi peningkatan jumlah penderita DM pada tahun 2030 dengan jumlah penderita DM meningkat menjadi 20,1 juta. Sedangkan data Riskesdas tahun 2013 menunjukkan peningkatan prevalensi DM di 17 propinsi seluruh Indonesia dari 1,1\% (2007) meningkat menjadi 2,1\% di tahun 2013 dari total penduduk sebanyak 250 juta jiwa. 
DM memunculkan berbagai macam komplikasi. Salah satu komplikasi DM adalah masalah kaki diabetik. Masalah kaki diabetik adalah penyebab utama mordibitas dan mortalitas serta membutuhkan biaya perawatan kesehatan yang tinggi pada pasien diabetes (Bowering \& Embil, 2013). Salah satu dari masalah kaki diabetik adalah Ulkus diabetes mellitus. Menurut Jeffcoate \& Harding (2003) Setiap diabetisi memiliki resiko $12-25 \%$ mengalami ulkus diabetes mellitus. Menurut Kemenkes RI (2014) persentase komplikasi dari DM yang mengalami rawat inap di RSUP Dr.Cipto Mangun Kusumo Jakarta selama tahun 2011 8,7\% pasien mengalami ulkus kaki. dengan angka Amputasi mencapai 1,3\%. Hal tersebut mempengaruhi kondisi diabetisi dan keluarganya (Pusat Data dan Informasi KemenKes, 2014).

Respon psikologis yang muncul pada keluarga salah satunya adalah ansietas. Keluarga yang merawat pasien dengan penyakit kronik, $40 \%$ nya mengalami ansietas dengan tanda tandanya merasa tegang / tidak enak, merasa takut jika sesuatu yang buruk terjadi, merasa khawatir, tidak nyaman, mual, sesak, dan gelisah.

Ulkus diabetes mellitus mengakibatkan beban sosial dan ekonomi bagi keluarganya (Sriyani dkk, 2013). Beban yang dirasakan oleh caregiver baik subyektif maupun obyektif tergantung dari dampak penyakit dan tingkat fungsional pasien. Tingkat beban subjektif akan dirasakan lebih besar pada caregiver yang mengasuh secara langsung dan membantu pasien dalam memenuhi kebutuhan sehari - harinya (Elmahdi dkk, 2010).

Penatalaksanaan Ulkus diabetes mellitus menurut Sudoyo (2009) dibedakan menjadi penatalaksanaan primer dan sekunder. penatalaksanaan sekunder dilakukan dengan pengelolaan holistik ulkus. Penanganan holistik, tidak hanya memberikan perawatan kaki pada pasien, akan tetapi juga memberikan perhatian pada modifikasi lingkungan terdekat pasien.

Keluarga adalah lingkungan terdekat diabetisi. Modifikasi lingkungan dilakukan guna meningkatkan koping keluarga pada pasien ulkus DM. Menurut Bomar (2010), promosi kesehatan diberikan kepada keluarga untuk membantu keluarga mengatasi masalah transisi keluarga dalam hal ini adalah masalah yang dihadapi keluarga ketika anggota keluarga mengalami masalah penyakit kronis.

Saat ini, promosi kesehatan telah dikembangkan dari jangka waktu yang pendek biasanya dikenal dengan pendidikan kesehatan, menjadi psikoedukasi keluarga dengan waktu pertemuan yang lebih lama dan materi yang lebih kompleks (Dixon, 2001). Menurut NAMI (National Alliance for The Mental Illnes) Psikoedukasi keluarga mengacu pada program yang memberikan pendidikan, dukungan dan bimbingan untuk keluarga.

Hasil studi pendahuluan yang dilakukan peneliti menunjukan 3 dari keluarga pasien ulkus diabetes mellitus merasa terbebani dengan masalah kesehatan dan masalah ekonomi yang terjadi akibat ulkus diabetes mellitus yang di alami oleh pasien. Berdasarkan latar belakang tersebut peneliti tertarik melakukan penelitian yang bertujuan untuk mengetahui efektifitas psikoedukasi keluarga dalam menurunkan beban keluarga dalam merawat pasien ulkus DM.

\section{METODE}

Desain penelitian ini menggunakan metode Quasy Experiment pre-post test with control group design. Jumlah sampel yang digunakan dalam kelompok eksperimen $10-20$ responden untuk masing - masing kelompok (sugiono, 2014). Sampel yang digunakan dalam penelitian ini sejumlah 30 responden (15 responden dalam masing - masing kelompok). Responden dalam penelitian ini adalah keluarga inti yang ikut merawat pasien ulkus Diabetes Melitus baik dirumah maupun menemani berobat. Ulkus yang di derita oleh pasien dari grade 1 - grade 5 dan pasien menderita ulkus kurang dari satu tahun hingga sepuluh tahun, Tehnik sampel yang digunakan adalah purposive sampel. Sampel dibagi menjadi 2 kelompok, masing-masing 15 orang pada kelompok kontrol dan pada kelompok intervensi.

Sebelum dilakukan intervensi pada masingmasing kelompok. Peneliti melakukan pre test yang berupa pengukuran terhadap beban keluarga. Menggunakan The Burden Scale untuk mengukur beban. The burden scale untuk mengukur beban pada keluarga yang 
merupakan hasil modifikasi dari dari The Burden Scale yang dikemukakan oleh Zarit (Andren \& Elhmstal, 2006) dan Montgomery Borgotta (Montgomerry \& Borgotta, 2000), terdiri dari 22 item pertanyaan. Masing-masing instrumen telah dinyatakan valid dan realiabel setelah diuji dengan menggunakan uji validitas dan reabilitas. Uji validitas dan reliabilitas dilakukan Nuraenah, Mustikasari, and Putri (2014) dengan hasil $\mathrm{r}$ table $(0,361) \mathrm{r}$ hitung $(0,765)$ dan $\mathrm{r}$ alpha / koefisien reliabilitas $(0,907)$. Hal tersebut menunjukkan kusioner valid dan reliable.

Setelah dilakukan pre test peneliti kemudian memberikan intervensi pada kelompok kontrol berupa penyuluhan kesehatan sebanyak 1 kali. Penyuluhan kesehatan yang diberikan berupa materi tentang ulkus DM dan perawatannya dengan metode ceramah dan pada akhir sesi diberikan kesempatan diskusi dan tanya jawab. Media yang digunakan dalam penyuluhan kesehatan ini adalah materi yang disampaikan dengan menggunakan lembar balik dan leaflet. Waktu yang dibutuhkan adalah 60 menit.
Kelompok intervensi diberikan terapi psikoedukasi keluarga selama 7 minggu dengan 5 sesi, setiap sesi 2 kali pertemuan dengan jeda waktu 2 hari, yaitu: identifikasi masalah keluarga, pendidikan kesehatan, manajemen ansietas, manajemen beban, evaluasi hambatan dan pemberdayaan keluarga dalam melakukan kolaborasi dengan petugas kesehatan dalam merawat pasien ulkus DM. Pelaksanaan terapi psikoedukasi ini dilakukan ke masing-masing keluarga dengan durasi waktu 30 - 60 menit tiap keluarga.

Setelah pemberian intervensi selesai peneliti melakukan post test berupa pengukuran kembali terhadap ansietas dan beban dengan menggunakan instrumen yang sama pada saat pre test.. Hasil penilaian terhadap ansietas dan beban pada saat pre test dan post test kemudian dianalisa dengan menggunakan uji univariat dan bivariat. Uji bivariat yang digunakan dalam penelitian ini adalah Uji $t$ test berpasangan dan Uji Mann Whitney.

\section{HASIL}

Beban keluarga sebelum dan sesudah psikoedukasi keluarga dapat dilihat pada tabel berikut.

Tabel 1.

Beban sebelum dan sesudah dilakukan psikoedukasi keluarga pada kelompok perlakuan dan pendidikan kesehatan pada kelompok kontrol $(\mathrm{n}=15, \mathrm{n}=15)$

\begin{tabular}{lcccc}
\hline Kelompok Perlakuan & P Shapiro Wilk & Mean & SD & $95 \%$ CI \\
\hline Beban Sebelum & 0,966 & 36,07 & 11,373 & $27,77-42,37$ \\
\hline Beban Sesudah & 0,106 & 23,87 & 10,405 & $18,10-29,63$ \\
\hline Kelompok Kontrol & & & & \\
\hline Beban Sebelum & 0,784 & 28,13 & 11,783 & $21,61-34,66$ \\
\hline Beban Sesudah & 0,153 & 26,33 & 9,759 & $20,93-31,78$
\end{tabular}

Berdasarkan tabel 1 dapat dilihat bahwa skor beban keluarga pada kelompok perlakuan. skor beban keluarga sebelum dilakukan pendidikan kesehatan (rata - rata) adalah 36,07.Rata - rata skor beban setelah diberi perlakuan adalah 23,87. Skor beban keluarga pada kelompok kontrol skor beban keluarga sebelum dilakukan pendidikan kesehatan (rata - rata) adalah 28,13 termasuk beban sedang. Sedangkan rata - rata skor beban

Tabel 2 .

Efektifitas psikoedukasi keluarga terhadap beban keluarga pada kelompok perlakuan dan pendidikan kesehatan pada kelompok kontrol $(n=15, n=15)$

\begin{tabular}{|c|c|c|c|c|c|}
\hline \multicolumn{3}{|c|}{ Kelompok perlakuan } & \multicolumn{3}{|c|}{ Kelompok kontrol } \\
\hline \multirow{2}{*}{$\begin{array}{l}\text { Perbedaan Mean } \\
\text { (CI 95\%) }\end{array}$} & \multicolumn{2}{|c|}{ Uji T-Berpasangan } & \multirow{2}{*}{$\begin{array}{l}\text { Perbedaan Mean } \\
\text { (CI 95\%) }\end{array}$} & \multicolumn{2}{|c|}{ Uji T-Berpasangan } \\
\hline & $\mathrm{t}$ & $\mathrm{P}$ & & $\mathrm{t}$ & $P$ \\
\hline 12,200 & 8,73 & 0,00 & 1,800 & 0,99 & 0,39 \\
\hline
\end{tabular}

setelah diberi perlakuan adalah 26,33 termasuk beban sedang. Berdasarkan uji normalitas dapat diketahui bahwa nilai signifikansi ansietas dan beban pada kelompok kontrol dan perlakuan Seluruhnya $\mathrm{p}>0,05$. Oleh karena itu seluruh kelompok variabel memiliki sebaran data yang normal, sehingga dapat digunakan uji t berpasangan. 
Hasil Uji t berpasangan (dependent simples $\mathrm{t}$ test) menunjukkan nilai thitung $>$ ttabel $(8,727>2,145)$ dan nilai signifikansi 0,000 $(\mathrm{p}<0,005)$ maka Ho ditolak, artinya terdapat perbedaan yang signifikan pada pengaruh psikoedukasi keluarga pada beban keluarga kelompok perlakuan. Pada kelompok kontrol,
Uji t berpasangan (dependent simples $t$ test) menunjukkan nilai thitung < ttabel $(0,990<$ $2,145)$ dan nilai signifikansi 0,393 (p > $0,005)$ maka H0 diterima, artinya tidak terdapat perbedaan yang signifikan pada pengaruh pendidikan kesehatan pada kelompok perlakuan.

Tabel. 3.

Perbedaan efektifitas psikoedukasi keluarga dan pendidikan kesehatan terhadap penurunan beban keluarga $(n=15, n=15)$

\begin{tabular}{|c|c|c|c|c|c|c|}
\hline \multirow[t]{2}{*}{ Kelompok } & \multirow[t]{2}{*}{ p Saphiro Wilk } & \multirow[t]{2}{*}{ Median } & \multirow[t]{2}{*}{ Min-Max } & \multirow[t]{2}{*}{ Rerata \pm Std.Dev } & \multicolumn{2}{|c|}{$\begin{array}{c}\text { Uji mann- } \\
\text { whitney }\end{array}$} \\
\hline & & & & & U & $p$ \\
\hline Perlakuan & 0,854 & 12,00 & $5,00-22,00$ & $12,20 \pm 5,41$ & 28,5 & \\
\hline Kontrol & 0,000 & 3,00 & $0,00-22,00$ & $4,60 \pm 5,51$ & & 0,0 \\
\hline
\end{tabular}
perlakuan $(0,854)$ dan selisih beban pada kelompok kontrol (0,000). Dilakukan transformasi data pada data selisih beban keluarga kelompok kontrol. akan tetapi, data masih tidak normal. Sehingga digunakan uji Maan Whitney untuk mengetahui efektifitas Psikoedukasi Keluarga pada beban keluarga. Secara keseluruhan perbedaan selisih rerata skor beban keluarga pada kelompok perlakuan dan kontrol (Psikoedukasi dan Pendidikan kesehatan) sesudah diberikan perlakuan menunjukkan nilai $\mathrm{p}=0,000(\mathrm{p}>$ $0,05)$. Hal ini bermakna bahwa terdapat perbedaan signifikan rerata skor beban keluarga pada kelompok perlakuan dan kelompok kontrol.

\section{PEMBAHASAN}

Hasil akhir penelitian ini didapatkan dari Uji selisih pre test dan post test antara variabel beban keluarga pada kelompok perlakuan dan kelompok kontrol menggunakan uji Mann Whitney. Uji Mann Whitney menunjukkan $\mathrm{p}$ value $(0,000)<\alpha(0.05)$. menunjukan psikoedukasi efektif dalam menurunkan beban keluarga.

Psikoedukasi keluarga merupakan bentuk dari terapi modalitas dengan fokus pengobatan adalah pada keluarga. Anggota keluarga (caregiver) dibantu untuk mengidentifikasi dan menemukan problem solving terjadap kondisi mal adaptif baik terhadap diri sendiri maupun berhubungan dengan orang lain (Townsend, 2014). Menurut Shives (2012) tujuan utama dari psikoedukasi keluarga adalah membawa

Psikoedukasi yang dilakukan pada keluarga pasien ulkus Diabetes Mellitus membantu caregiver untuk mengidentifikasi masalah selama merawat pasien ulkus. Masalah tersebut seperti gula darah pasien yang tidak stabil, luka yang tak kunjung sembuh, kondisi fisik pasien yang tidak stabil yang mengakibatkan rawat inap hingga masalah biaya perawatan ulkus diabetes mellitus. Hal tersebut menyebabkan ansietas dan beban pada keluarga pasien ulkus Diabetes Mellitus.

Psikoedukasi keluarga pada penelitian ini dilaksanakan dalam lima sesi. Masing masing sesi dilakukan selama $30-60$ menit. Pada sesi pertama, terapis mengkaji masalah yang dialami caregiver selama merawat pasien ulkus diabetes mellitus. Pada sesi ini caregiver mendapatkan penjelasan tentang psikoedukasi keluarga, tujuan yang ingin dicapai dan manfaat nya bagi keluarga.

Sesi kedua, berfokus pada masalah yang dialami oleh pasien ulkus Diabetes Mellitus. Pada sesi ini, keluarga mendapatkan tambahan. Sesi ketiga caregiver mendapatkan penegetahuan terkait ansietas dan cara mengatasinya. sesi keempat caregiver diberikan informasi tentang beban keluarga dan cara mengelola beban. Caregiver melakukan diskusi dengan terapis terkait beban keluarga yang saat ini dialami dalam merawat pasien ulkus diabetes Mellitus. Sesi kelima caregiver bersama terapis akan mendiskusikan sumber - sumber 
dalam keluarga yang mengalami hambatan. Hambatan yang dimaksudkan adalah hambatan dalam berhubungan dengan petugas kesehatan dan mendapatkan perawatan dari petugas kesehatan.

Psikoedukasi keluarga adalah salah satu bentuk promosi kesehatan pada keluarga guna meningkatkan kemampuan keluarga untuk berpartisipasi dalam menyelesaikan masalah yang terjadi didalam keluarga (Okpokoro dkk,2014). Penelitian yang dilakukan oleh Nurbani (2009) tentang pengaruh psikoedukasi keluarga terhadap ansietas dan beban keluarga (caregiver) dalam merawat pasien Stroke di RSUPN Dr.Ciptomangunkusumo Jakarta. Penelitian ini menggunakan desain Quasi Experiment Pre - post with control Group Design dengan responden 22 pada kelompok intervensi dan 23 responden pada kelompok kontrol. hasil penelitian ini adalah beban mengalami penurunan tetapi tidak bermakna.

Penelitian yang dilakukan Ronesmaharani (2015) tentang pengaruh psikodukasi keluarga dalam menurunkan ansietas dan beban keluarga yang merawat anak dengan retradasi mental. Desain penelitian yang digunakan adalah Quasi Experiment Pre post with control Group Design. Pengambilan sampel dengan menggunakan teknik simple random sampling dangan 12 responden perlakuan dan 12 responden kontrol. Hasil penelitian ini adalah tingkat ansietas mengalami penurunan yang bermakna. Beban keluarga mengalami penurunan akan tetapi tidak bermakna.

Kedua penelitian tersebut menggunakan skala ordinal dan menggunakan uji non parametrik. Hal ini menyebabkan hasil ukur terbatas hanya dalam pengelompokan dan kurang spesifiknya penurunan ansietas dan beban yang terjadi setelah dilakukannya psikoedukasi keluarga. Pada skala ukur ordinal menunjukan penurunan ansietas dari sedang menjadi ringan sedangkan pada beban terjadi penurunan tingkat beban. Akan tetapi ketika menggunakan sekala ukur interval / rasio dapat diketahui lebih rinci berapa skor penurunan ansietas dan beban keluarga. Hal ini berdampak pula dengan uji statistika yang digunakan. Data ordinal dianalisis menggunakan uji non parametrik. Sedangkan data interval / rasio memungkinkan menggunakan uji parametrik jika distribusi data normal. Hal ini memungkinkan pada hasil yang lebih baik pada uji parametrik.

Hasil uji parametrik pada penelitian ini menunjukkan terdapat penurunan rata - rata beban yang bermakna pada kelompok perlakuan dibandingkan dengan kelompok kontrol. hal tersebut memperlihatkan psikoedukasi keluarga efektif dalam menurunkan beban pada keluarga / caregiver pasien ulkus Diabetes Mellitus di Malang.

\section{SIMPULAN}

Terdapat penurunan beban yang bermakna pada keluarga dalam merawat penderita Ulkus Diabetes Mellitus sebelum dan sesudah dilakukan psikoedukasi keluarga.

\section{DAFTAR PUSTAKA}

Ambarwati, Weny. (2015). Efektivitas Program Psikoedukasi Kelompok dalam menurunkan beban Psikologis pada family caregiver diabetes mellitus.

Andrén, S. \& Elsmstal (2006) Family Caregivers of Persons with Dementia. Experiences of Burden, Satisfaction and Psychosocial Intervention. Dissertation, Lund University, Lund.

American Psychiatric Association. (2014). Beck Depression Inventory (BDI). Dilihat 4 Februari 2016 jam 20.15 WIB.http://www.apa.org/pi/about/public ations/careg ivers/practicesettings/assessment/tools/beck depression

Bhattacharjee, Dipanjan, Rai, Altul Kumar, Singh, Narendra Kumar, Kumar, Pradeep, Munda, Sanjay Kumar, \& Das, Basudeb. (2011). Psychoeducation : A Measure to Streng Psychiatric Treatment. Delhi Psychiatric Journal.

Bomar, P.J. (2004). Promoting Health in Families: Applying Family Research and Theory to Nursing Practice. Philadelphia: W.B. Sounders Company.

Bowering, Keith \& Jhon M.Embil. (2013). Clinical Practice Guidelines Foot Care. Canadian Journal of Diabetes, Elsevier 
Bustan 2007, Epidemiologi Penyakit Tidak Menular, Rineka Cipta, Jakarta.

Dahlan, M. Sopiyudin, 2013. Statitiska Untuk Kedokteran dan Kesehatan. Jakarta: Salemba Medika.

Dewi, E. I. (2011). Pengaruh terapi kelompok suportif terhadap beban dan tingkat ansietas keluarga dalam merawat anak tunagrahita di sekolah luar biasa (SLB) kabupaten banyumas. Tesis. Jakarta: Fakultas Ilmu Keperawatan UI.

Dixon, Lisa, William R. McFarlane, Harriet Lefley, Alicia Lucksted, Michael Cohen, Ian Falloon, . . . Diane Sondheimer. (2001). Evidence-Based Practices for Service to Families of People With Psychiatric Disabilities. Psychiatric Service, 52(7).

Ellen P. Lukens, \& William. (2004). Psychoeducation as Evidence-Based Practice: Considerations for Practice, Research, and Policy.

Elmahdi, Mohammed, Foad kamel, Ali esmael, Mohammed lotfi, Ahmad Kamel \& Ayman elhosini. (2010). Burden of care on female caregivers and its relation to psychiatric mordibity. Middle East Curr Pshychiatry.

Federation, International Diabetes. (2013). IDF diabetes atlas six editions.

Fernandez, O., Seravin L G, Ana G S, Aurora O G, Martha A S, \& Ana Maria G P. (1999). Integrated Psychological Treatment for Schizophrenic patient. Psychology in Spain.

Frykberg, RG. (2002). Diabetic Foot Ulcer : Pathogenesis and management. Am Fm Psysician. Vol 66, Number 9.

Gayle E. Reiber, PhD, MPH., Benjamin A. Lipsky, MD, FACP., \& Gary W. Gibbons, MD. (1998). The Burden of Diabetic Foot Ulcers. Excerpta Medica.

Georgios, \& Biroo, Miklos. (2010). Psychological aspects of adolescents with diabetes mellitus Procedia ,Elsevier.

Hastono, Sutanto Priyo. (2007). Analisis Data Kesehatan. Depok : Fakultas Kesehatan Masyarakat Universitas Indonesia

Khalil, asad., Zaki, Abel rehim, megala, geber, gamal \& rohoma. (2015). Prevalence of Diabetic Foot Disorder and related risk factor among Egyptian subjects with diabetes. Primary Care Diabetes.

Kaplan,H.I, Sadock,B. J. (2010). Buku ajar Psikiatri Klinis. $2^{\text {nd }}$ ed. Jakarta: EGC

Komisi Nasional Etik Penelitian Kesehatan. (2011). Buku Ajar Etik Penelitian Kesehatan. Malang. UB Press.

Lestari, Arena. (2011). PengaruhTerapi Psikoedukasi Keluarga terhadap pengetahuan dan tingkat anxietas keluarga dalam merawat anggota keluarga yang mengalami tuberkolosis paru di kota bandar lampung.

Madigan, K. , Egan, D Brennan, S.Hil, B Maguire, F Horgan, C Flood, Kinsella, O'Callaghan. (2012). A randomised controlled trial of carer - focussed multy family group psychoeducation in bipolar disorder. European Psychiatry. ScienceDirect.

M Mazlina, A S Shamsul, F A Saini Jeffery (2011). Health-related Quality of Life in Patients with Diabetic Foot Problems in Malaysia. Med J Malaysia.

Mohr, W.K. (2006). Psychiatric mental health nursing. $6^{\text {th }}$ ed. Phiadelpia: Lippincott Williams dan Wilkins.

Nauli, fathra annisa. (2011). Pengaruh logotherapi lansia dan psikoedukasi keluarga terhadap depresi dan kemampuan makna hidup pada lansia di kelurahan katulampa Bogor timur. Thesis UI.

Nurbani. (2009). Pengaruh Psikoedukasi Keluarga terhadap masalah Psikososial ansietas dan beban keluarga (Care giver) 
dalam merawat pasien Stroke di RSUPN Dr Ciptomangunkusumo Jakarta.

Notoatmodjo, soekidjo,. (2012). Metodelogi Penelitian Kesehatan . Jakarta. PT Rineka Cipta

Pariante, C.M, Carpiniello. (1996). Family burden in relatives of schizophrenics and of people with mental retardation: a comparative study. Eur Psychiatry Journal. 11. $381-385$.

Ramaiah, S 2006, Diabetes Cara Mengetahui Gejala Diabetes dan Menditeksinya Sejak Dini, Trans. Joeliani L, Lamtiur, K, PT Buana Ilmu Populer. Jakarta.

RI, Pusat Data Dan Informasi Kementrian Kesehatan. (2014). Situasi Dan Analisis DIABETES, Waspada Diabetes Eat Well Life well.

Rosmaharani, Shanti. (2015). Pengaruh Psikoedukasi keluarga terhadap perubahan tingkat kecemasan dan persepsi beban keluarga dalam merawat anak dengan retradasi mental di SLB negeri kabupaten jombang.

Shimazu, Kae, Shimodera, hinji, Mino, Yoshio, Nishida, Atsushi, Kamimura, Naoto, Sawada, Ken, . . Inoue, Shimpei. (2011). Family psychoeducation for major depression: randomised controlled trial.

Shives, R, 2012, Basic concept of psychiatric and Mental Health Nursing, Alih Bahasa Kuncara, Jakarta: EGC.

Sriyani, Kumarasinghe A., Sudharsani washalatantrhri, Priyadharsikha, Shamini. (2013). Predictorof diabetic Foot and Leg Ulcers in a Developing Country with a repid increase in the Prevelence of Diabetes Mellitus. Ploss One

Stuart, G. W. \& Laraia, M. T. (2009). Principles and practice of psychiatric nursing. $9^{\text {th }}$ ed. St. Louis: Mosby Yaer B.

Stuart, G. W. \& Laraia, M. T. (2013). Principles and practice of psychiatric nursing. $10^{\text {th }}$ ed. St. Louis: Mosby Yaer B.

Stuart, G. W. \& Laraia, M. T. (2016). Prinsip dan Praktik Keperawatan Kesehatn jiwa STUART Edisi Indoesia. Singapore, Elsevier

Sudoyo, et all 2009, Buku Ajar Ilmu Penyakit Dalam Vol.3, Edk 5, EGC, Jakarta.

Sukandar, E. Y. 2008. ISO Farmakoterapi. PT. ISFI Penerbitan: Jakarta

Tjokroprawiro, A 2006, Hidup Sehat dan Bahagia Bersama Diabetes Melitus, PT Gramedia Pustaka Utama, Jakarta.

Thakur, megha (2015). Diabetes and depression : A review With special focus on india. Global Journal Of medicine and Public Health

Townsend, M. C, 2014, Psychiatric Mental Healt Nursing : Concepts of Care in Evidence-BasedPractice (7th ed.), Philadelphia : F.A. Davis

Vileiky, Loretta. (2005). The Psycho-social Impac of Diabetes foot Damage.

William J Jeffcoate, Keith G Harding. (2003). Diabetic foot ulcer (review). The Lancet.

Wright, L.M., \& Leahey, M. (2009). Nurses and Families: A Guide to Family Assessment and Intervention (6th ed.). Philadelphia, PA: F.A. Davis.

Zung, William W.K. (1971). A rating instrument for anxiety disorders. Psychosomatics. 
Jurnal Ilmu Keperawatan Jiwa Volume 3 No 1, Hal 9 - 16, Februari 2020

Persatuan Perawat Nasional Indonesia Jawa Tengah 